\title{
Relationship Between Morbidity and Mortality and HbA1c Levels in Diabetic Patients Undergoing Major Surgery
}

\author{
Begum Seyda Avci1, Tayyibe Saler1, Akkan Avci2, Mehmet Bankir1, Zeynep Tüzün1, Hakan Nazik3 and Faruk Karateke4
}

\author{
1Department of Internal Medicine / Emergency Medicine2 / Obstetric and Gynecology ${ }^{3}$, Health Science University, \\ Adana City Research and Training Hospital, Adana, Turkey \\ ${ }^{4}$ Department of General Surgery, University of Istinye, Live Hospital, Mersin, Turkey
}

\begin{abstract}
Objective: To investigate the relationship between the preoperative $\mathrm{HbA} 1 \mathrm{c}$ levels and the complications and mortality rates in the postoperative period in patients with diabetes undergoing a major surgical treatment.

Study Design: Descriptive study

Place and Duration of Study: Deparment of Internal Medicine, Adana Numune Research and Training Hospital, Turkey, from January 2015 to December 2016.

Methodology: Diabetic patients, who underwent major surgery (a large resection) having preoperative HbA1c levels, were considered. A total of 1,013 patients, whose file data were completely accessed, were included in the study. Preoperative $\mathrm{HbA1c}$ levels of the patients and complications seen within the first 7 and first 30 days postoperatively were recorded.

Results: Fourty-nine (4.8\%) of the patients were exitus in the hospital, while $964(95.2 \%)$ of the patients were discharged. Preoperative $\mathrm{HbA} 1 \mathrm{c}$ levels of the patients were found to be predictive marker of mortality and complications in the first 7 and 30 days postoperatively $(p<0.001)$.

Conclusion: $\mathrm{HbA} 1 \mathrm{c}$ levels are important in preoperative surgical risk assessment in diabetic patients. Better provision of long-term glycemic control in patients planned elective surgery and have low levels of HbA1c may significantly reduce postoperative mortality and complications.
\end{abstract}

Key Words: Diabetes mellitus, HbA1c, Mortality, Postoperative complication, Major surgery.

How to cite this article: Avci BS, Saler T, Avci A, Bankir M, Tüzün Z, Nazik H, Karateke F. Relationship between morbidity and mortality and HbA1c levels in diabetic patients undergoing major surgery. J Coll Physicians Surg Pak 2019; 29(11):1043-7.

\section{INTRODUCTION}

Diabetes is a complex and chronic disease that requires continuous medical care with a multi-factor risk reduction strategy based on glycemic control. ${ }^{1}$ Major surgery is any invasive operation that includes a large resection. Chronic complications of diabetes are secondary conditions that occur later and cause serious problems. Chronic complications of diabetes can be prevented or delayed by good glycemic control. These chronic complications of diabetic patients can also affect major surgical outcomes. One of the two parameters showing glycemic control in diabetic patients is the plasma glucose level, while the other is the glycolated hemoglobin $(\mathrm{HbA} 1 \mathrm{c})$ level. High $\mathrm{HbA} 1 \mathrm{c}$ values are particularly associated with increased complications associated with microvascular and cardiovascular diseases. ${ }^{2}$ According to the American Diabetes Association (ADA) 2017 guidelines, the target glycemic control index

Correspondence to: Dr. Akkan Avci, Department of Emergency Medicine, Science Health University, Adana City Research and Training Hospital, Adana, Turkey.

E-mail:drakkanavci@gmail.com

Received: April 23, 2019; Revised: July 26, 2019;

Accepted: September 20, 2019 is considered to be below $7 \%(53 \mathrm{mmol} / \mathrm{mol})$ of $\mathrm{HbA} 1 \mathrm{c}$ in non-pregnant adult diabetic patients. ${ }^{3}$

There are limited number of studies reporting the cut-off level value of $\mathrm{HbA} 1 \mathrm{c}$ to predict mortality and complications in patients undergoing major surgery.

In this study, the aim was to determine the cut-off value of $\mathrm{HbA1c}$ levels in adult diabetic patients undergoing major surgery

\section{METHODOLOGY}

The study was approved by Ethics Committee of Non-Interventional Clinical Researches of Çukurova University. Data collection was started after receiving the appropriate permission from the Health Science University, Adana Numune Training and Research Hospital Administration.

It was a descriptive study, retrospectively collecting data from 8,754 patients, who underwent major surgery from January 2015 to December 2016 in our hospital. Patients whose preoperative $\mathrm{HbA} 1 \mathrm{c}$ levels were recorded in the hospital information system before the planned surgery, were considered. Patients who were diagnosed with type $2 \mathrm{DM}$, whose HbA1c levels were measured preoperatively, who underwent elective major 
surgery, were over 18 years of age, hemoglobin levels above $10 \mathrm{mg} / \mathrm{dl}$ and had complete file history, were included in the study. Patients with diabetes other than type 2 DM, under 18 years of age, who underwent emergency major surgery, patients with chronic liver disease, patients with chronic renal failure, patients whose data files were inaccessible or incomplete, hemoglobin levels under $10 \mathrm{mg} / \mathrm{dl}$, and those without preoperative $\mathrm{HbA} 1 \mathrm{c}$ values, were excluded from the study.

The age, comorbid diseases, history of surgery were recorded on the study form from the patients' files. Hemoglobin, hematocrit, white blood cell count, thrombocyte count, fasting blood glucose, blood urea nitrogen, creatinine, aspartate aminotransferase (AST), alanine aminotransferase (ALT), sodium, potassium and $\mathrm{HbA1C}$ values were recorded from the laboratory before the operation. The epicrisis forms of the patients recorded their diagnosis, type and group of operation, duration of postoperative ward and/or intensive care admission, outcome within the first 7 and first 30 days after the operation. The complications of the patients who developed complications, were recorded.

Additionally, the patients were divided into four groups. Group 1 included patients with HbA1c levels below $7 \%$. Group 2 included patients with $\mathrm{HbA} 1 \mathrm{c}$ levels between $7 \%$ and $7.99 \%$. Group 3 included patients with $\mathrm{HbA} 1 \mathrm{c}$ levels between $8 \%$ and $8.99 \%$. Group 4 included patients with $\mathrm{HbA} 1 \mathrm{c}$ levels more than $9 \%$. The mortality and complications seen in the first 7 and 30 days between groups were compared.

SPSS 15 package programme was used for the statistical evaluation of the data obtained in the study (SPSS Inc, Chicago, Illinois, USA). Continuous data were summarised as mean, standard deviation, while categorical data were summarised as number and percentage. The receiver operating characteristic (ROC) curve was used to investigate the accuracy of $\mathrm{HbA} 1 \mathrm{c}$ in measuring the complications and mortalities. The criterion for best test definition according to this method was accepted as the sensitivity $100 \%$, the false positivity of zero (1-specificity $=0)$, the area under the curve $(A \cup C)$ as 1 and the diagnostic value of AUC as $p<0.05$. When the cut-off value was determined, the highest sensitivity in the ROC curve and the Youden index of the specificity point were used. Sensitivity, specificity parameters were presented as a table with $95 \%$ confidence interval.

\section{RESULTS}

A total of 1,013 patients were included in the study; while $484(47.8 \%)$ of the patients were females and 529 $(52.2 \%)$ were males. The mean age of the patients was $55.88 \pm 12.634$ years. As for the indication of major surgery, $45.7 \% \quad(n=463)$ cardiovascular diseases were found to be the most frequently operated group. Malignant tumors were second with $18.9 \%(n=191)$ and obesity surgeries were third with $16.1 \%(n=163)$.

When the complication rates of the patients were examined within the first 7 days, 868 patients $(85.7 \%)$ had no complications and 113 patients $(11.2 \%)$ had complications. A total of 32 patients (3.2\%) died during this period. When the patients were examined according to complication, wound infection ( $\mathrm{N}=24,2.4 \%)$ was the most common. When the complication rates of the patients were examined within the first 30 days, 806 patients $(79.6 \%)$ had no complications and 159 patients $(15.7 \%)$ had complications. A total of 48 patients $(4.7 \%)$ died during this period. When the patients were examined according to complication, wound infection $(n=60,5.9 \%)$ was the most common (Table I).

ROC analyses were performed for the role of preoperative $\mathrm{HbA} 1 \mathrm{c}$ values of patients in predicting deaths within the first 7 days and within the first 30 days. Within the first 7 days, the area under the curve was found to

Table I: Distribution of complications in the first seven (7) days.

\begin{tabular}{|c|c|c|c|c|}
\hline & $\begin{array}{c}\text { Number } \\
\text { (for } 7 \text { days) } \\
(\mathrm{N})\end{array}$ & $\begin{array}{c}\text { Percentage } \\
\text { (for } 7 \text { days) } \\
(\%)\end{array}$ & $\begin{array}{c}\text { Number } \\
\text { (for } 30 \text { days) } \\
(\mathrm{N})\end{array}$ & $\begin{array}{c}\text { Percentage } \\
\text { (for } 30 \text { days) } \\
(\%)\end{array}$ \\
\hline None & 868 & 85.7 & 806 & 79.6 \\
\hline Exitus & 32 & 3.2 & 48 & 4.7 \\
\hline Acute coronary syndrome & 2 & 0.2 & 1 & 0.1 \\
\hline ARDS* & 5 & 0.5 & 2 & 0.2 \\
\hline Arryhthmia & 8 & 0.8 & None & None \\
\hline Acute renal failure & 16 & 1.6 & 3 & 0.3 \\
\hline Bleeding & 8 & 0.8 & 1 & 0.1 \\
\hline Cerebrovasculer attack & None & None & 2 & 0.2 \\
\hline Delirium & 1 & 0.1 & None & None \\
\hline $\mathrm{DIC}^{* *}$ & 1 & 0.1 & None & None \\
\hline Hypoglisemia & 1 & 0.1 & None & None \\
\hline Hypocalcemia & 1 & 0.1 & None & None \\
\hline Hypotansion & 2 & 0.2 & None & None \\
\hline Haemothoraks & None & None & 1 & 0.1 \\
\hline Hyponatremia & None & None & 2 & 0.2 \\
\hline Hydrocephalus & None & None & 3 & 0.3 \\
\hline Infective endocarditis & 2 & 0.2 & None & None \\
\hline Ileus & 1 & 0.1 & 2 & 0.2 \\
\hline Iskemic hepatitis & 2 & 0.2 & None & None \\
\hline IIPS ${ }^{* * *}$ & 1 & 0.1 & None & None \\
\hline Mesenteric ischemia & None & None & 1 & 0.1 \\
\hline Pancreatitis & 1 & 0.1 & 1 & 0.1 \\
\hline Pneumonia & 15 & 1.5 & 43 & 4.2 \\
\hline Sepsis & 3 & 0.3 & 1 & 0.1 \\
\hline Respiratuar failure & 2 & 0.2 & None & None \\
\hline Cerebrovascular attack & 5 & 0.5 & None & None \\
\hline Tamponade & None & None & 2 & 0.2 \\
\hline Wound infection & 24 & 2.4 & 60 & 5.9 \\
\hline Other infection ${ }^{\star * * *}$ & 12 & 1.2 & 34 & 3.3 \\
\hline Total & 1013 & 100,0 & 1013 & 100,0 \\
\hline
\end{tabular}


Table II: Analysis of preoperative HbA1c value predicting deaths, occurrence of complications, presence of wound infection and total infection in the first 7 and first 30 days postoperatively.

\begin{tabular}{|c|c|c|c|c|c|c|}
\hline Variable & $\mathrm{AUC} \pm \mathrm{SD}(95 \% \mathrm{Cl})$ & Upper-Lower Bound & p-value & Cut-off for $\mathrm{HbA} 1 \mathrm{c}$ & Sensitivity & Specificity \\
\hline Predicting deaths within the first 7 days & $0.617 \pm 0.046$ & $0.526-0.708$ & $<0.024$ & & & \\
\hline Predicting deaths within the first 30 days & $0.607 \pm 0.041$ & $0.527-0.687$ & $<0.012$ & & & \\
\hline Predicting the occurrence of complications in the first 7 days & $0.653 \pm 0.023$ & $0.607-0.698$ & $<0.001$ & & & \\
\hline Predicting the occurrence of complications in the first 30 days & $0.785 \pm 0.018$ & $0.751-0.820$ & $<0.001$ & $7.45 \%$ & $63.8 \%$ & $78.8 \%$ \\
\hline Predicting the presence of wound infection in the first 7 days & $0.737 \pm 0.039$ & $0.661-0.812$ & $<0.001$ & $7.65 \%$ & $53.3 \%$ & $73.3 \%$ \\
\hline Predicting the presence of wound infection in the first 30 days & $0.788 \pm 0.026$ & $0.738-0.839$ & $<0.001$ & $7.85 \%$ & $65.0 \%$ & $77.1 \%$ \\
\hline Predicting the presence of total infection in the first 7 days & $0.668 \pm 0.034$ & $0.601-0.735$ & $<0.001$ & & & \\
\hline Predicting the presence of total infection in the first 30 days & $0.815 \pm 0.018$ & $0.780-0.851$ & $<0.001$ & $7.45 \%$ & $71.5 \%$ & $76.6 \%$ \\
\hline
\end{tabular}

AUC: Area Under the Curve; SD: Standard Deviation; Cl: Confidence Interval.

be 0.617 (95\% confidence interval, in the 52.6-70.8 interval, $p<0.024$, Table II). Area under the curve for the prediction of mortality within the first 30 days was found to be 0.607 (95\% confidence interval, in the $52.7-68.7$ interval, $p<0.012$, Table II).

$\mathrm{ROC}$ analyses were performed for the role of preoperative $\mathrm{HbA} 1 \mathrm{c}$ values in predicting the occurrence of complications in the first 7 days and first 30 days. The area under the curve was found to be $0.653(95 \%$ confidence interval, in the 60.7-69.8 interval, $p<0,001$ ) in the measurements made in determining the complications within the first 7 days (Table II).

The area under the curve was found to be $0.785(95 \%$ confidence interval, in the 75.1-82.0 interval, $p<0.001$ ) in the measurements made in determining the complications within the first 30 days. When the cut-off value of $\mathrm{HbA} 1 \mathrm{c}$ was $7.45 \%$, sensitivity was $63.8 \%$ and specificity was $78.8 \%$ (Table II).

$\mathrm{ROC}$ analyses were performed to determine role of preoperative $\mathrm{HbA} 1 \mathrm{c}$ levels in predicting the presence of wound infection in the first 7 days and first 30 days. In the measurements made within the first 7 days for determining wound infection, the area under the curve was found to be 0.737 (95\% confidence interval, in the 66.1 - 81.2 interval, $p<0,001)$. When the cut-off value of $\mathrm{HbA} 1 \mathrm{c}$ was $7.65 \%$, sensitivity was $53.3 \%$ and specificity was $73.3 \%$ (Table II).

In the measurements made within the first 30 days for determining wound infection, the area under the curve was found to be 0.788 (95\% confidence interval, in the 73.8 - 83.9 interval, $p<0.001)$. When the cut-off value of $\mathrm{HbA} 1 \mathrm{c}$ was $7.85 \%$, sensitivity was $65.0 \%$ and specificity was $77.1 \%$ (Table II).

$\mathrm{ROC}$ analyses were performed to determine role of preoperative $\mathrm{HbA} 1 \mathrm{c}$ levels in predicting the presence of total infection in the first 7 days and first 30 days. In the measurements made within the first 7 days for determining total infection, the area under the curve was found to be 0.668 (95\% confidence interval, in the 60.1 73.5 interval, $p<0.0001$, Table II).

In the measurements made within the first 30 days for determining total infection, the area under the curve was found to be 0.815 (95\% confidence interval, in the 78.0 -
85.1 interval, $p<0.0001)$. When the cut-off value of HbA1c was $7.45 \%$, sensitivity was $71.5 \%$ and specificity was $76.6 \%$ (Table II).

\section{DISCUSSION}

HbA1c has been used for years in diabetic patients' follow-up; and in recent years, it has become a test used to diagnose diabetes. ${ }^{3}$ Regulation of preoperative fasting blood glucose levels of patients scheduled for surgery is a known practice. However, even if the fasting blood sugar is regulated, the effect of long-term glycemic control is not clear. There are a limited number of studies on this topic. This work on long-term blood glucose regulation and the complications occuring in patients undergoing major surgical procedures, it was found that preoperative $\mathrm{HbA} 1 \mathrm{c}$ measures can be an indicator of the incidence of mortality, complications, wound infection and total infection.

Zhong and colleagues documented a total of 32 researches, including cohort and meta-analysis studies. While the results of three studies showed the association of mortality with $\mathrm{HbA} 1 \mathrm{c}$ in oncologic surgery patients was not significant. There was a significant correlation between the results of 6 studies examining mortality in patients undergoing cardiovascular surgery and the results of 11 investigators studying its relationship with all deaths. ${ }^{4}$ Although there was no statistically significant difference among groups for the first 7 and first 30 days mortality in present study, when the ROC analysis of the relationship between the mortality rate in the first 7 days and first 30 days with $\mathrm{HbA} 1 \mathrm{c}$ elevation was examined by ROC analysis, the mortality prediction was more significantly higher. According to these results, $\mathrm{HbA} 1 \mathrm{c}$ levels might be a predictor marker for predicting postoperative mortality.

High $\mathrm{HbA} 1 \mathrm{c}$ levels $(>7 \%)$ are associated with higher incidence of micro- and macro-vascular complications in patients with type 2 DM.5,6 Many studies have shown that complications such as postoperative infections, ${ }^{7-11}$ wound-related complications, ${ }^{12,13}$ and deep venous thrombosis ${ }^{14}$ are more common in diabetic patients than in non-diabetic patients. HbA1c serves as a primary determinant of long-term complications of DM, and fasting blood glucose measurements serve as determinants of 
short-term complications. These two measurements are complementary because while intervening stress factors can affect fasting blood sugar, $\mathrm{HbA1c}$ is unaffected by this. ${ }^{15,16} \mathrm{HbA} 1 \mathrm{c}$ was an important predictor of all postoperative complications. Neuronal, vascular, cardiac damage, which are caused by diabetes in patients with uncontrolled chronic glycemia, perioperative anesthetic agent use and additional serious effects of these agents, may be a cause of these complications. Long-term high blood sugar exposure in diabetic patients results in tissue-level glycolysis without micro- or macro-vascular complications becoming obvious. This damage may prepare the ground for the development of various complications in high stress situations such as major surgery.

There are many studies investigating the role of $\mathrm{HbA} 1 \mathrm{c}$ in predicting postoperative wound infection in diabetic patients in different surgical groups. Han and colleagues used $\mathrm{HbA} 1 \mathrm{c}$ levels in association with glycemic control with arthroplasty surgery in diabetic patients. The results obtained indicate that there is a significant increase in the risk of wound infection in the patient group with a $\mathrm{HbA} 1 \mathrm{c}$ level of $8 \%$ or more. ${ }^{12}$ Another study with cardiac surgery reported that patients with $\mathrm{HbA} 1 \mathrm{c}>8 \%$ had twice as many wound infections and this difference was statistically significant. 17 Gatti et al. evaluated the effect of $\mathrm{HbA} 1 \mathrm{c}$ level in determining the risk of sternal wound infection with $\mathrm{HbA} 1 \mathrm{c}$ in patients undergoing coronary surgery. In patients with $\mathrm{HbA} 1 \mathrm{c}$ levels over $8.6 \%$, the risk of serious sternal wound infection has been implicated and the importance of detecting preoperative $\mathrm{HbA} 1 \mathrm{c}$ levels was stressed. As a result of the multivariate analysis they conducted, they also suggested that $\mathrm{HbA} 1 \mathrm{c}$ is one of the strongest predictors of sternal wound infection. ${ }^{18}$ According to the results of our study, the increase in $\mathrm{HbA} 1 \mathrm{c}$ levels was associated with wound infection, total infection and other complications. Due to this results, preoperative $\mathrm{HbA} 1 \mathrm{c}$ levels might be independent and powerful predictor for predicting postoperative wound infection, total infection and other complications. There are a number of factors that affect the appearance of infection at higher levels in patients with uncontrolled glycemia prior to surgery. These include genetic susceptibility, impaired cellular and humoral immune defence mechanisms, local factors such as reduced blood flow and neuropathy, and degenerations that occur in the regulation of collagen synthesis. 19,20

Preoperative evaluation and reduction of postoperative complications and mortality in diabetic patients undergoing major surgery are very important. For this purpose, it is recommended that patients' fasting blood sugar level is regulated in routine practice. However, $\mathrm{HbA1c}$ values can be used effectively in the preliminary view of postoperative complications and mortality risk. Better maintenance of long-term glycemic control in patients with elective surgery and high $\mathrm{HbA} 1 \mathrm{c}$ levels may significantly reduce postoperative mortality and complications. In particular, cut-off values in terms of preoperative prediction of wound infection, pneumonia, and total infection burden were determined. It is anticipated that detection of patients with values above the cut-off values of $\mathrm{HbA} 1 \mathrm{c}$ obtained before operation and lowering the $\mathrm{HbA} 1 \mathrm{c}$ levels of these patients to below the cut-off value may seriously reduce postoperative wound infection, pneumonia and total infection burden.

This study was planned retrospectively. A number of genetic and acquired conditions, as well as drugs, may interfere with $\mathrm{HbA} 1 \mathrm{c}$ levels and cause inappropriately high or low HbA1c measurements, were not included in this study.

\section{CONCLUSION}

Blood glucose level, and perioperative blood glucose monitoring and control are important in the preoperative period; but it is also important to determine whether or not long term glycemic control is optimal. Therefore, we think that it may be safer to maintain $\mathrm{HbA} 1 \mathrm{c}$ values within normal limits in patients undergoing major surgery.

\section{ETHICAL APPROVAL:}

The study was approved by Ethics Committee of NonInterventional Clinical Researches of Çukurova University.

\section{PATIENTS' CONSENT:}

As the study was conducted retrospectively, data was obtained from hospital otomation system and archive after obtaining necessary permissions from hospital management.

\section{CONFLICT OF INTEREST:}

Authors declared no conflict of interest.

\section{AUTHORS' CONTRIBUTION:}

BSA, ST, AA: Made substantial contributions to the conception or design, acquisition, analysis, or interpretation of data for the work, drafted the work and revised it critically for important intellectual content; approved the final version to be published; agreed to be accountable for all aspects of the work in ensuring that questions related to the accuracy or integrity of any part of the work are appropriately investigated and resolved.

TZ, BM, NH: Planned and designed the work; analysed, or interpreted data for the work; drafted the work or revised it critically for important intellectual content.

ST, KF: Drafted the work and revised it critically for important intellectual content.

\section{REFERENCES}

1. American Diabetes Association: Standards of Medical Care in Diabetes-2017; 40(Suppl. 1):S48-S56.

2. American Diabetes Association: Standards of Medical Care in Diabetes; Diagnosis and Classification of Diabetes Mellitus. Diabetes Care. 2016. 
3. Zhong GC, Ye MX, Cheng JH, Zhao Y, Gong JP. HbA1C and risks of all-cause and cause-specific death in subjects without known diabetes: A dose-response meta-analysis of prospective cohort studies. Sci Rep 2016; 6:24071.

4. Diabetes Control and Complications Trial Research Group, Nathan DM, Genuth S, Lachin J, Cleary P, Crofford O. The effect of intensive treatment of diabetes on the development and progression of long-term complications in insulindependent diabetes mellitus. N Engl J Med 1993; 329:977-86.

5. UK Prospective Diabetes Study Group. Intensive blood group with sulphonylureas or insulin compared with conventional treatment and risk of complications in patients with type 2 diabetes (UKPDS 33). Lancet 1998; 352:837-53.

6. Jamsen E, Nevalainen P, Eskelinen A, Huotari K, Kalliovalkama J, Moilanen T. Obesity, diabetes, and preoperative hyperglycemia as predictors of periprosthetic joint infection: A single-center analysis of 7,181 primary hip and knee replacements for osteoarthritis. J Bone Joint Surg Am 2012; 94:e101.

7. Namba RS, Inacio MC, Paxton EW. Risk factors associated with deep surgical site infections after primary total knee arthroplasty: An analysis of 56,216 knees. J Bone Joint Surg Am 2013; 95:775-782.

8. Pruzansky JS, Bronson MJ, Grelsamer RP, Strauss E, Moucha CS. Prevalence of modifiable surgical site infection risk factors in hip and knee joint arthroplasty patients at an urban academic hospital. J Arthroplasty 2014; 29:272-6.

9. Reategui D, Sanchez-Etayo G, Nunez E, Tio M, Popescu D, Nunez M, et al. Perioperative hyperglycaemia and incidence of postoperative complications in patients under-going total knee arthroplasty. Knee Surg Sports Traumatol Arthrosc 2015; 23: 2026-31.

10. Yang K, Yeo SJ, Lee BP, Lo NN. Total knee arthroplasty in diabetic patients: A study of 109 consecutive cases. J Arthroplasty 2001; 16:102-6.
11. England SP, Stern SH, Insall JN, Windsor RE. Total knee arthroplasty in diabetes mellitus. Clin Orthop Relat Res 1990; 260: 130-4.

12. Han HS, Kang SB. Relations between long-term glycemic control and postoperative wound and infectious complications after total knee arthroplasty in type 2 diabetics. Clin Orthop Surg 2013; 5:118-23

13. Wang S, Zhao Y. Diabetes mellitus and the incidence of deep vein thrombosis after total knee arthroplasty: A retrospective study. J Arthroplasty 2013; 28:595-7.

14. Zhao Z, Wang S, Ma W, Kong G, Zhang S, Tang Y, et al. Diabetes mellitus increases the incidence of deep vein thrombosis after total knee arthroplasty. Arch Orthop Trauma Surg 2014; 134:79-83.

15. Khaw KT, Wareham N, Bingham S, Luben R, Welch A, Day N. Association of hemoglobin A1c with cardiovascular disease and mortality in adults: The European prospective investigation into cancer in Norfolk. Ann Intern Med 2004; 141:413-20.

16. Barr RG, Nathan DM, Meigs JB, Singer DE. Tests of glycemia for the diagnosis of type 2 diabetes mellitus. Ann Intern Med 2002; 137:263-272.

17. McMurry JF Jr. Wound healing with diabetes mellitus: Better glucose control for better wound healing in diabetes. Surg Clin North Am 1984; 64:769-78.

18. Gatti G, Perrotti A, Reichart D, Maschietto L, Onorati F, Chocron S, et al. Glycated hemoglobin and risk of sternal wound infection after isolated coronary surgery. Circ J 2016; 81:36-43.

19. Brenner RE, Riemenschneider B, Blum W, Mörike M, Teller WM, Pirsig W, et al. Defective stimulation of proliferation and collagen biosynthesis of human bone cells by serum from diabetic patients. Acta Endocrinol (Copenh) 1992; 127:509-14.

20. Robertson HD, Polk HC, Jr. The mechanism of infection in patients with diabetes mellitus: A review of leukocyte malfunction. Surgery 1974; 75:123-8. ............ 